\title{
Identifikasi dan Kepadatan Mikroplastik pada Sedimen di Mempawah Mangrove Park (MMP) Kabupaten Mempawah, Kalimantan Barat
}

\author{
Chinda Setia Lestari $^{1}$, Warsidah ${ }^{*}$, Syarif Irwan Nurdiansyah ${ }^{1}$ \\ 1 Program studi Ilmu Kelautan, FMIPA, Universitas Tanjunpura, Pontianak- \\ Indonesia \\ *Correspondence email: Warsidah \\ 凶arsidah@fmipa.untan.ac.id
}

Received:26 September 2019- Accepted: 2 October 2019

Published: 31 October 2019 (C) Author(s) 2019. This article is open access

\begin{abstract}
Salah satu ekosistem mangrove yang diduga tercemar mikroplastik yaitu, Mempawah Mangrove Park (MMP) di Kabupaten Mempawah, Kalimantan Barat. Tujuan dari penelitian yaitu untuk mengetahui jenis dan kepadatan mikroplastik pada sedimen di Mempawah Mangrove Park (MMP), Kabupaten Mempawah, Kalimantan Barat. Hasil penelitian mendapatkan empat jenis mikroplastik, yaitu fiber, fragmen, film dan microbead. Mikroplastik memiliki kepadatan tertinggi pada stasiun I, diikuti oleh stasiun III, stasiun IV dan stasiun II. Identifikasi mikroplastik di Mempawah Mangrove Park (MMP) menunjukkan kedalaman 20-30 cm memiliki kepadatan mikroplastik lebih tinggi dibandingkan kedalaman $0-10 \mathrm{~cm}$ dan $10-20 \mathrm{~cm}$. Uji Kruskal-Wallis yang telah dilakukan menunjukkan kepadatan jumlah mikroplastik antar stasiun dan kepadatan mikroplastik antar kedalaman tidak menunjukkan perbedaan yang signifikan (Asimpg. Sig. 0,059>0,05).
\end{abstract}

Keywords: Mangrove, Sedimen, Mikroplastik, Kabupaten Mempawah

\section{Pendahuluan}

Ekosistem mangrove telah mengalami pencemaran yang diakibatkan polusi yang berasal dari daratan. Dampak kontaminasi tersebut terjadi secara global maupun lokal yang disebabkan oleh aktivitas manusia di ekosistem mangrove, pantai dan lautan terbuka (Nor and Obbard, 2014; Leite et al., 2014; Cózar et al., 2014). Pencemaran makroplastik maupun mikroplastik diperkirakan mencapai 7.000 sampai 35.000 ton (Cózar et al., 2014; Cole et al., 2011; Lima et al., 2014).

Menurut Kementrian Lingkungan Hidup dan Kehutanan, sampah plastik hasil dari 100 toko atau anggota Asosiasi Pengusaha Ritel Indonesia (APRINDO) dalam waktu 1 tahun mencapai 10,95 juta lembar sampah (setara dengan 65,7 hektar kantong plastik). Plastik merupakan polimer sintetis dan memiliki karakteristik bahan yang cocok digunakan dalam kehidupan sehari-hari (Derraik, 2002). Terhitung 1,9 juta ton plastik diproduksi selama tahun 2013 di Indonesia (Kemenperin, 2013). Thompson (2006) memperkirakan bahwa $10 \%$ dari semua plastik yang baru diproduksi akan dibuang melalui sungai dan berakhir di laut. Rendahnya tingkat pemulihan dan pembuangan limbah plastik yang tidak tepat menghasilkan akumulasi plastik di lingkungan yang menyebabkan 
munculnya jenis kontaminan baru disebut sebagai mikroplastik.

Mikroplastik telah ditemukan secara luas di lingkungan, terutama di sedimen pantai dan lautan di seluruh dunia. Partikel-partikel mikroplastik di lingkungan akuatik terbentuk dalam ukuran, densitas, komposisi kimia, dan bentuk yang berbeda (Duis and Coors, 2016). Mikroplastik dapat ditemukan dalam produk penggunaan sehari-hari seperti facial scrub, cat atau dari pecahan makroplastik yang lebih besar (mikroplastik sekunder) (Andrady, 2011; Wagner et al., 2014).

Mangrove berperan penting bagi ekosistem seperti produksi ikan, tempat pembiakan dan tempat mencari makan bagi fauna, keanekaragaman hayati tinggi dan sebagai perlindungan garis pantai dari erosi (Joshi and Kale, 2013). Kawasan mangrove di Kabupaten Mempawah, Kalimantan Barat merupakan daerah ekowisata yang berkonsep edukasi. Kawasan mangrove ini merupakan ekowisata yang ramai dikunjungi, baik dari masyarakat setempat maupun masyarakat luar. Hal ini menyebabkan terjadinya penumpukan sampah di kawasan Mempawah Mangrove Park (MMP) yang berasal dari masyarakat yang berkunjung maupun sampah yang terbawa arus dari laut.

Potensi sampah menjadi masalah utama pencemaran pesisir, namun sedikit informasi kuantitatif mengenai pencemaran sampah spesifik lokasi, khususnya mikroplastik di ekosistem mangrove Mempawah. Permasalahan sampah laut juga belum menjadi perhatian dalam menentukan strategi pengelolaan ekosistem mangrove di Kabupaten Mempawah, Kalimantan Barat. Kurangnya informasi menjadikan penelitian mengenai identifikasi dan kepadatan mikroplastik pada sedimen di Mempawah Mangrove Park (MMP), Kabupaten Mempawah penting untuk dilakukan.

\section{Metode}

\subsection{Waktu dan tempat}

Penelitian ini dilakukan dari Bulan Januari sampai Maret 2019. Sampel sedimen diambil pada tanggal 17 Januari 2019 di Mempawah Mangrove Park (MMP), Kabupaten Mempawah, Kalimantan Barat (Gambar 1). Identifikasi mikroplastik dilakukan di laboratorium Pertanian, analisis jenis sedimen dilakukan di laboratorium Mekanika Tanah Fakultas Teknik, persiapan sampel dan analisis data dilakukan di laboratorium Ilmu Kelautan dan laboratorium Zoologi
Fakultas Matematika Ilmu Pengetahuan Alam, Universitas Tanjungpura.

\subsection{Prosedur Penelitian \\ 2.2.1 Penentuan titik sampling}

Penentuan lokasi penelitia menggunakan metode purposive sampling, yang terdiri dari empat stasiun dengan melihat kondisi geografis dan rona lingkungan yang sesuai dengan tujuan penelitian, kemudian titik koordinat lokasi ditentukan menggunakan GPS. Stasiun I berlokasi dekat dengan aktivitas penduduk, stasiun II dekat dengan dermaga, stasiun III berlokasi sejajar dengan pesisir dan stasiun IV berlokasi jauh dari aktivitas penduduk.

\subsubsection{Pengambilan sampel}

Pengambilan sampel sedimen menggunakan coring dengan panjang $(0-50 \mathrm{~cm})$. Sampel diambil pada tiga kedalaman yaitu 10, 20 dan 30 di setiap stasiun yang selanjutnya dimasukkan ke dalam plastik sampel dan diberi label. Penempatan coring dilakukan pada substrat yang tidak terdapat perakaran mangrove untuk mempermudah pengambilan sampel menggunakan coring.

\subsubsection{Pembuatan larutan $\mathrm{NaCl}$ (komersial)}

Larutan $\mathrm{NaCl}$ (komersial) dibuat dengan mencampurkan sodium klorida (garam meja komersial) $1 \mathrm{~kg}$ dengan air destilasi (3 liter) dan diaduk menggunakan stirrer hingga homogen.

\subsubsection{Pemisahan partikel mikroplastik}

Pemisahan partikel mikroplastik (0.045-5 $\mathrm{mm})$ dari sedimen mangrove dilakukan dengan 5 tahap, yaitu pengeringan, pengurangan volume, pemisahan densitas, penyaringan, dan pemilahan secara visual

\subsubsection{Jenis sedimen}

Pengambilan sampel sedimen dilakukan pada setiap stasiun berdasarkan kedalaman. Analisis butir sampel sedimen menggunakan metode pengayakan basah berdasarkan skala Wentworth.

\subsection{Analisis Data}

Data kepadatan mikroplastik dianalisis secara statistik. Uji Kruskal-Wallis digunakan untuk memeriksa adanya beda nyata nonparametrik meliputi kepadatan dan komposisi mikroplastik antar stasiun dan 
Tabel 1. Jenis-Jenis Mikroplastik yang ditemukan di Mempawah Mangrove Park (MMP)

\begin{tabular}{lllccc}
\hline \multirow{2}{*}{ No } & \multirow{2}{*}{ Mikroplastik } & \multicolumn{5}{c}{ Stasiun } \\
\cline { 3 - 6 } & & I & II & III & IV \\
\hline 1. & Fiber & + & + & + & + \\
2. & Fragmen & + & + & - & + \\
3. & Film & + & + & + & - \\
4. & Microbead & + & + & + & + \\
\hline \multicolumn{2}{l}{ Keterangan : (+) Positif (ada) (-) Negatif (tidak ada) }
\end{tabular}
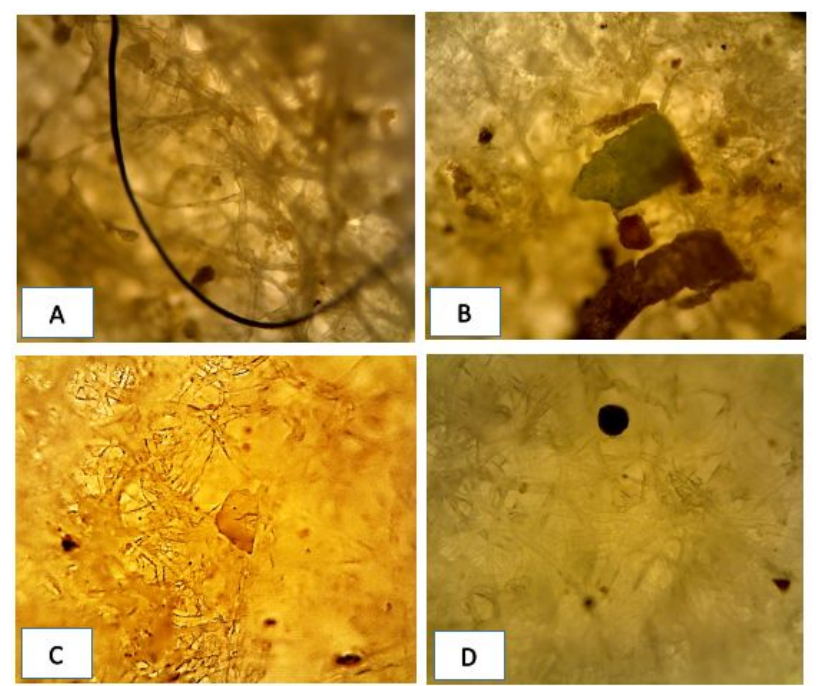

Gambar 1. Jenis-jenis mikroplastik yang ditemukan di Mempawah Mangrove Park (MMP) (a) fiber (b) fragmen (c) film (d) microbead

kedalaman. Jika hasil pengujian berbeda nyata, dilanjutkan dengan Uji Mann-Whitney untuk mengidentifikasi beda nyata antara dua kelompok (Claessens et al., 2011).

\section{Hasil dan Pembahasan}

\subsection{Jenis Mikroplastik}

Mikroplastik pada sedimen di Mempawah Mangrove Park (MMP) terdiri dari empat jenis yaitu fiber, fragmen, film dan microbead (Tabel 1). Mikroplastik fiber dan microbead ditemukan pada semua stasiun. Jenis fragmen hanya ditemukan pada stasiun I, II dan IV dan film hanya ditemukan pada stasiun I, II dan III.

Kawasan Mempawah Mangrove Park (MMP) memiliki jenis mikroplastik yang lebih banyak dibandingkan beberapa penelitian yang telah disebutkan sebelumnya. Hal ini diduga disebabkan oleh beberapa faktor, seperti jenis substrat dan kondisi perairan.

\subsection{Kepadatan mikroplastik setiap stasiun}

Kepadatan mikroplastik tertinggi di kawasan Mempawah Mangrove Park (MMP) berada pada stasiun I (0,953 partikel/gr), yang diikuti oleh stasiun III (0,193 partikel/gr), stasiun IV (0,147 partikel/gr) dan stasiun II $(0,100 \mathrm{partikel} / \mathrm{gr})$ (Gambar 4.2). Tingginya mikroplastik pada stasiun I diduga karena dekat dengan aktivitas warga atau pengunjung sehingga sumber partikel mikroplastik lebih banyak dibandingkan stasiun lainnya, misalnya sampah plastik domestik, benang pancing, jaring nelayan dan lain-lain. Jenis mikroplastik pada stasiun I sebagian besar terdiri dari fiber karena aktivitas manusia umumnya menggunakan fiber (produksi, pencucian dan tekstil). Berdasarkan penelitian yang dilakukan oleh Nor and Obbard (2014), mikroplastik jenis fiber paling banyak ditemukan di mangrove Singapura pada lokasi yang berdekatan dengan aktivitas warga, seperti dari peternakan ikan dan area rekreasi pantai.

Stasiun II memiliki kepadatan mikroplastik yang paling rendah, dengan fiber sebagai mikroplastik yang memiliki kepadatan paling tinggi. Lokasi stasiun II yang tergenang oleh air dan diduga masih mendapat pengaruh pasang surut menjadikan partikel mikroplastik di lokasi tersebut dapat 


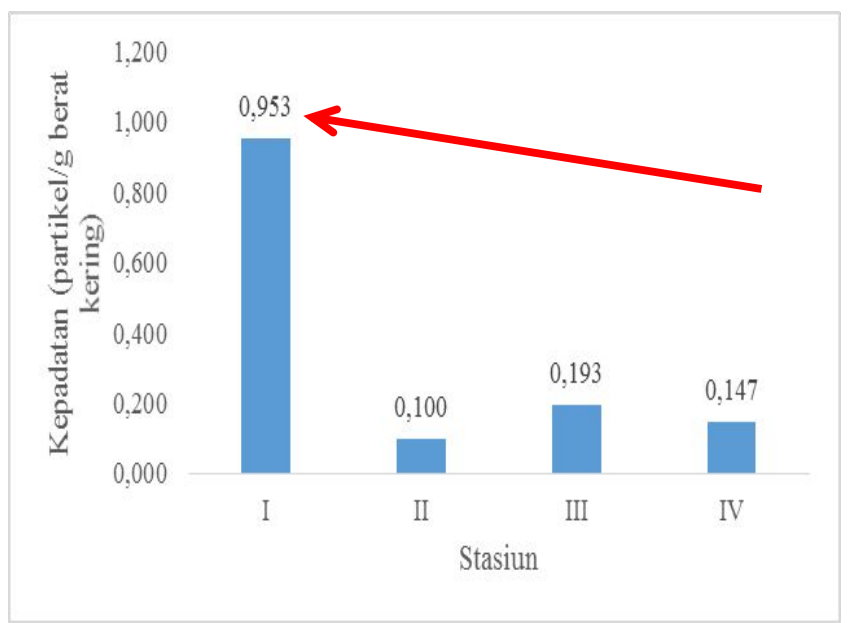

Gambar 2. Kepadatan mikroplastik pada setiap stasiun di Mempawah Mangrove Park (MMP) Kabupaten Mempawah, Kalimantan Barat

terbawa arus ke sedimen. Rendahnya kepadatan mikroplastik pada stasiun II dapat juga disebabkan oleh aktivitas manusia yang rendah di kawasan tersebut. Menurut Nor and Obbard (2014), rendahnya tingkat aktivitas manusia dapat menyebabkan rendahya konsentrasi mikroplastik di suatu kawasan.

Kepadatan mikroplastik pada setiap stasiun menunjukkan nilai yang berbeda, namun perbedaan tersebut tidak signifikan. Uji Kruskal-Wallis yang telah dilakukan menunjukkan kepadatan jumlah mikroplastik antar stasiun tidak berbeda nyata (Asimpg. Sig. 0,059 >0,05).

\subsection{Kepadatan mikroplastik berdasarkan kedalaman}

Hasil dentifikasi mikroplastik pada sedimen di Mempawah Mangrove Park (MMP), menunjukkan lapisan sedimen di kedalaman 20-30 cm memiliki kepadatan mikroplastik lebih tinggi $(0,707$ partikel/gr) dibandingkan kedalaman $0-10 \mathrm{~cm}(0,327 \mathrm{partikel} / \mathrm{gr})$ dan $10-20 \mathrm{~cm} \quad(0,360 \mathrm{partikel} / \mathrm{gr})$. Tingginya jumlah partikel mikroplastik pada lapisan bawah dibandingkan lapisan atas diduga disebabkan oleh distribusi vertikal. Mikroplastik memiliki struktur yang kecil sehingga cenderung pindah lebih jauh ke lapisan sedimen lebih dalam. Menurut Vianello et al. (2013) pindahnya partikel mikroplastik ke lapisan yang lebih dalam disebabkan oleh bioturbasi atau aliran air, misalnya peristiwa badai atau banjir serta transportasi oleh binatang. Ukuran partikel mikroplastik dan sedimen yang sama juga memungkinkan terjadinya penumpukan mikroplastik bersamaan dengan penumpukan sedimen sehingga akumulasi mikroplastik di lapisan lebih dalam lebih banyak dibandingkan lapisan atas (Vianello et al., 2013).

Kepadatan mikroplastik antar kedalaman menunjukkan nilai yang tidak signifikan. Uji

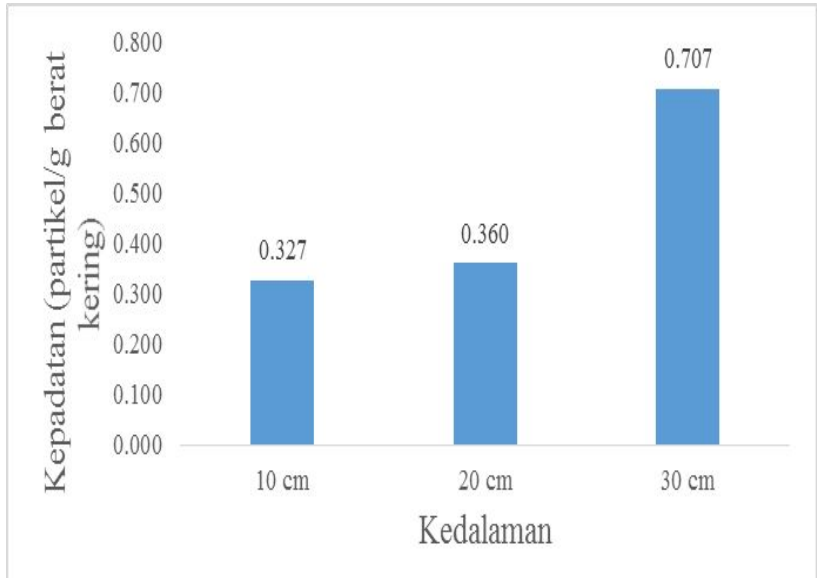

Gambar 3. Kepadatan mikroplastik berdasarkan kedalaman di Mempawah Mangrove Park (MMP) Kabupaten Mempawah, Kalimantan Barat 


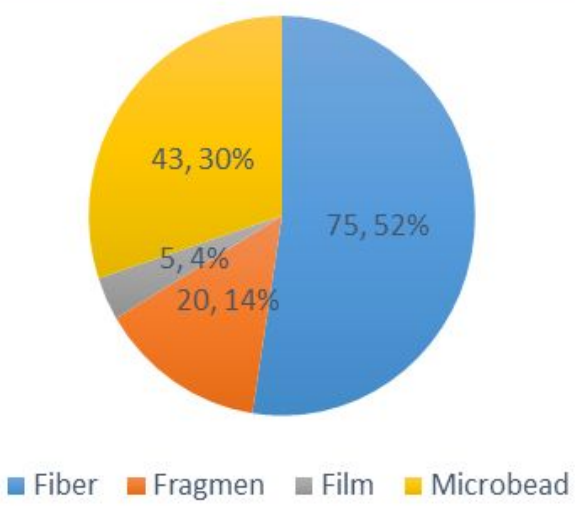

Gambar 4. Kepadatan mikroplastik jenis filamen, fiber, fragmen, film dan microbead pada setiap stasiun

Kruskal-Wallis yang telah dilakukan menunjukkan kepadatan mikroplastik antar kedalaman tidak berbeda nyata (Asimpg. Sig. $0,059>0,05)$.

\subsection{Kepadatan mikroplastik berdasarkan jenis}

Mikroplastik dengan kepadatan tertinggi adalah jenis fiber $(75,52 \%)$, diikuti microbead $(43,30 \%)$, fragmen $(20,14 \%)$ dan film $(5,4 \%)$ (Gambar 4.4). Nor and Obbard (2014) juga mendapatkan jenis fiber sebagai mikroplastik yang dominan di ekosistem mangrove di Singapura (72\%) yang diikuti oleh film $(23,3 \%)$ dan microbead $(4,7 \%)$. Martin et al. (2017) menemukan di Irlandia bahwa persentase fiber sejumlah $85 \%$ dan fragmen $15 \%$, fiber memiliki bentuk seperti serat dan mudah terakumulasi pada sedimen. Fiber yang ditemukan memiliki morfologi yang mirip dengan serabut atau jaring nelayan dengan warna biru tua, biru muda dan merah.

Fiber banyak digunakan pada pembuatan pakaian, perahu, jaring nelayan dan peralatan rumah tangga, sehingga mikroplastik jenis fiber lebih mudah ditemukan dan tersebar luas baik di sedimen maupun di perairan. Browne (2015) menyatakan bahwa mikroplastik fiber yang ditemukan di habitat laut dapat berasal dari limbah domestik. Kegiatan laut seperti perikanan merupakan sumber fiber karena sebagian besar jaring ikan terbuat dari fiber (Browne et al., 2011; Mason et al., 2016; Zhao et al., 2018).

Microbead diidentifikasi sebagai polimer polipropilen dan polimerilena yang terdiri dari fraksi plastik keras yang berasal dari berbagai sumber. Microbead yang ditemukan memiliki bentuk yang mirip dengan yang ditemukan di Great Lakes (Eriksen et al., 2013) dan sangat mirip dengan yang digunakan dalam produk konsumen (Fendall and Sewell, 2009). Microbead juga dapat mewakili mikroplastik primer, seperti yang digunakan dalam produk samping pribadi (kosmetik) (Cole et al., 2011).

Fragmen diketahui berasal dari hasil potongan produk plastik dan kerusakan plastik kaku dengan polimer sintetis yang sangat kuat. Sumber fragmen yang ditemukan di sedimen dapat berasal dari sampah plastik yang dihasilkan oleh aktivitas manusia setempat (Mason et al., 2012).

Jenis mikroplastik film paling sedikit ditemukan di kawasan Mempawah Mangrove Park (MMP) dibandingkan mikroplastik jenis lainnya. Mikroplastik film diidentifikasi sebagai polimer polietilen dan polipropil-ene, yang biasa digunakan dalam bungkus plastik dan tas. Mikroplastik ini mudah hancur dan memiliki densitas yang rendah. Menurut (Kingfisher, 2011), film merupakan polimer plastik sekunder yang berasal dari fragmentasi kantong plastik atau plastik kemasan dan memiliki densitas rendah.

\section{Kesimpulan}

Mikroplastik yang ditemukan pada sedimen di Mempawah Mangrove Park (MMP) Kabupaten Mempawah, Kalimantan Barat terdiri dari empat jenis yaitu fiber, fragmen, film dan microbead. Fiber merupakan jenis mikroplastik yang paling banyak ditemukan pada sedimen di kawasan Mempawah Mangrove Park (MMP). Kepadatan mikroplastik tertinggi berada pada stasiun I dan pada kedalaman $10 \mathrm{~cm}$ 


\section{Daftar Pustaka}

Andrady, A.L., 2011, Microplastics in the Marine Environment, J. Mar. Pollut. Bull., 62: 1596-1605

Browne, M.A; Crump, P; Niven, S.J; Teuten, E; Tonkin, A; Galloway, T. and Thompson, R., 2011, Accumulation of Microplastic on Shorelines Woldwide: sources and sinks, J. Envir. Sci. Technol., 45(21): 9175-9179

Browne, M. A., 2015, Sources and Pathways of Microplastics to Habitats, Marine Anthropogenic Litter, Springer International Publishing, 229-244.

Claessens, M; Meester, D.S; Landuyt, V.L; Clerck, D.K. and Janssen, C.R., 2011, Occurrence and Distribution of Microplastics in Marine Sediments Along the Belgian Coast, J. Mar. Pollut. Bull., 62: 2199-2204

Cole, M., Lindeque, P; Halsband, C. and Galloway, T.S., 2011, Microplastics as Contaminants in the Marine Environment, J. Mar. Pollut. Bull., 62: 2588-2597

Cózar, A; Echevarría, F; González-Gordillo, J.I; Irigoien, X.B; Úbeda, S; Hernández-León, Á.T; Palma, S.; Navarro, J., García-de-Lomas, A., Ruiz, M.L; Fernández, D.P. and Duarte, C.M., 2014, Plastic Debris in the Open Ocean, Proceedings of the National Academy of Sciences of the United States of America., 111(28): 10239-10244

Derraik, J.G.B., 2002, The Pollution of the Marine Environment by Plastic Debris, J. Mar. Pollut. Bull., 44: 842-852

Duis, K. and Coors, A., 2016, Microplastics in the Aquatic and Terrestrial Environment: Sources (with a specific focus on personal care products), Fate and Effects, J. Environ. Scien. Eur., 28: 2-25

Eriksen, M; Mason, S.; Wilson, S; Box, C; Zellers, A; Edwards,W., 2013, Microplastic Pollution in the Surface Waters of the Laurentian Great Lakes, J. Mar. Pollut. Bull., 77: 177-182

Fendall, L.S. and Sewell, M.A., 2009, Contributing to Marine Pollution by Washing Your Face: microplastics in facial cleansers, J. Mar. Pollut. Bull., 58(8): 1225-1228

Joshi, V.U. and Kale, V.S., 2013, Environmental Conflicts in Coastal Metropolitan Cities in India: case studies of mumbai and chennai metropolitan regions, SECOA., 4: 320-354

Kemenperin (Kementerian Perindustrian dan Perdagangan)., 2013, Konsumsi Plastik 1,9 juta ton.

Lima, A.R.A; Costa, M.F. and Barletta, M., 2014, Distribution Patterns of Microplastics within the Plankton of a Tropical Estuary, J. Environ. Res., 132: 146-155

Leite, A.S; Santos, L.L; Costa, Y. and Hatje, V; 2014, Influence of Proximity to an Urban Center in the Pattern of Contamination by
Marine Debris, J. Mar. Pollut. Bull., 81: 242-247

Nor, N.H.M. and Obbard, J.P., 2014 , Microplastics in Singapore Coastal Mangrove Ecosystems, J. Mar. Pollut. Bull., 79(1-2): 278-283

Martin, J., Lusher, A., Thompson, R.C. and Morley, A., 2017, The Deposition and Accumalation of Microplastic in Marine Sediment and Bottom Water from the Irish Continental Shelf, J. Nature., 7: 1-9

Mason, C.F., 1981, Biology of Freshwater Pollution Longman, New York.

Vinello, A; Boldrin, A; Guerrieri. P; Moschino, V; Rella, R; Sturaro, A. and Ros, D.L., 2013, Microplastic Particles in Sediments of Lagoon of Venice, Italy: First observations on occurrence, spatial patterns and identification. Venice: CNR. Estuarine, Coastal an

Zhao, J; Ran, W; Teng, J; Liu, Y; Liu, H; Yin, X; Cao, R; Wang, Q., 2018, Microplastic Pollution in Sediments from the Bohai Sea and the Yellow Sea. China, J. Sci. Total Environ., 640-641, 637-645 